\title{
Abortion services in Canada: access and safety
}

\author{
Laura Schummers ScD, Wendy V. Norman MD MHSc
}

Cite as: CMAJ 2019 May 13;191:E517-8. doi: 10.1503/cmaj.190477

See related article at www.cmaj.ca/lookup/doi/10.1503/cmaj.181288

I $\mathrm{n}$ linked research, Liu and colleagues ${ }^{1}$ analyzed Ontario administrative health data to investigate the safety of surgical abortion. Their meticulous analysis found that, in Ontario, surgical abortions were highly safe with very rare severe adverse events -1.6 per 1000 abortions (95\% confidence interval $[\mathrm{Cl}] 1.5-1.7)$. This finding, that severe morbidity following surgical abortion in Ontario is consistent with reported rates globally, ${ }^{2,3}$ provides evidence to guide clinicians and patients considering the limited options available to women with an abnormal or unintended pregnancy. However, the present study does not consider the decision-making context facing patients with an abnormal or unintended pregnancy, which limits our ability to draw conclusions that can inform practice and choice.

Liu and colleagues ${ }^{1}$ compared abortions performed by the 79 physicians who provide $90 \%$ of surgical abortions in Ontario with those provided by 400 physicians who provide the remaining $10 \%$. Unsurprisingly, abortions performed by low-volume providers were more likely to take place in hospital versus purpose-specific urban abortion clinics (86.2\% v. 19.1\%). Furthermore, abortions performed by low-volume providers were more likely to be for residents in rural areas $(11.3 \%$ low volume v. $5.1 \%$ high volume) and to occur at 15 weeks or more gestation (3.8\% v. $2.4 \%$ ), perhaps reflecting delays in accessing abortion by rural residents. The authors found small absolute increases in the rate of uncommon severe adverse events in the lower volume group, 3.7 per 1000 abortions (95\% Cl 3.2-4.2) compared with 1.4 per 1000 abortions $(95 \% \mathrm{Cl} 1.3-1.5)$ among high-volume providers. ${ }^{1}$

A patient with an abnormal or unintended pregnancy may choose only between abortion and birth. The small absolute risk differences comparing abortion providers by volume must be interpreted in the context of these limited choices. The reported risk differences are smaller than those comparing birth and abortion. Pregnancies that continue to birth have a rate of severe maternal morbidity eightfold higher than that reported in the linked study of abortion. A well-designed national surveillance study of all births in Canada ${ }^{4}$ showed a severe maternal morbidity rate of 13.8 per 1000 births. Studies in the United States corroborate this pattern. ${ }^{2}$ Compared with 1.6 per 1000 reported in this article, or even 3.7 per 1000 among the low-volume providers, surgical abortion would be a rational choice even when the only consideration is maternal health.

\section{KEY POINTS}

- Surgical abortion in Ontario is a safe procedure, with complication rates for surgical abortion consistent with known standards.

- An induced abortion with the nearest provider may be the safest option for a woman with an abnormal or unintended pregnancy, and may entail lower complication rates than delaying an abortion or carrying a pregnancy to birth.

- Preventing unintended pregnancy is a preferred approach to support optimal health outcomes.

- There is a need to define and validate standard measures for identifying and reporting abortion-related adverse events and morbidities for the Canadian context.

The risk differences reported in the linked research ${ }^{1}$ are smaller than those attributable to abortion occurring at later gestational ages, for example, as may result if there is delay in accessing a high-volume service. Both complications and severe adverse events associated with surgical abortion increase markedly with increasing gestational age. Case fatality rates increase from 0.3 per 100000 abortions at 8 weeks or less gestation to 0.7 at $9-10$ weeks, 1.1 at $11-12$ weeks, 2.2 at $13-15$ weeks and 6.9 at $16-20$ weeks. $^{5}$

Accessing timely abortion services can be difficult in Canada, particularly for those in rural settings. In 2016, the United Nations (UN) Human Rights Office of the High Commissioner adjured Canada to improve equitable access to abortion. ${ }^{6}$ Rural residents often travel long distances and have substantial wait times to reach abortion services. A 2013 examination ${ }^{7}$ of geographical disparities in abortion access in Canada found that $18.1 \%$ of women travelled more than $100 \mathrm{~km}$ to access abortion. Women who travelled were more likely to report that their abortion occurred later than they would have preferred, which may indicate that geographical disparities are associated with abortions at later gestational ages.

Although the authors of the linked study ${ }^{1}$ cited the standard for reporting abortion complications, Procedural Abortion Incident Reporting and Surveillance Framework, ${ }^{8}$ the study's outcomes were not defined using this approach. This framework "distinguishes incidents resulting from procedural abortion care (adverse events) from morbidity related to pregnancy, the abortion 
process and other non-abortion-related conditions." ${ }^{8}$ The current study, ${ }^{1}$ instead, created a new outcome measure for abortion complications that combined 2 measures of severe obstetric maternal morbidity with mortality from any cause. This comprises both adverse events and morbidities related to pregnancy and abortion, including those unlikely to be related to the care provided or the techniques of the procedure (for example, the authors retained all deaths while acknowledging that most deaths were due to assault or suicide); they reported 28 deaths in their population of 529 141, a rate of 5.3 all-cause deaths per 100000 abortions. ${ }^{1}$ In contrast, the US Centers for Disease Control and Prevention meticulously defined specific abortion-related mortality ${ }^{9}$ and recently reported that "The national legal induced abortion case-fatality rate for 2008-2014 was 0.62 legal induced abortion-related deaths per 100000 reported legal abortions." ${ }^{9}$ Furthermore, the authors of the linked research did not include diagnostic codes specific to abortion procedures (International Statistical Classification of Diseases and Related Health Problems, 10th Revision code 008) in their outcome. It is not clear whether using a measure of abortion-specific adverse events in line with standard approaches ${ }^{8,9}$ would have changed observed associations. An appropriate gold-standard approach to identifying abortion complications with Canadian administrative data has yet to be developed.

The authors of the linked research concluded that their findings support centralization of abortion services within specialized abortion clinics staffed by high-volume providers. ${ }^{1}$ However, choosing between a high- versus low-volume provider may not be realistic for many patients in rural locations. In these settings, a surgical abortion by a low-volume provider (which may already require substantial travel) may be the most expeditious, and thus safest, option. Compared with delaying abortion to a later gestational age while arranging travel and time away from home or work to reach a high-volume provider or to continue the pregnancy to birth, the small absolute increase in risk associated with a low-volume provider may be immaterial. Moreover, primary care provision of medical abortion using mifepristone will enable earlier, safer abortion, ${ }^{10}$ and clinicians and patients are likely to see a heartening trend in this direction in coming years.

A pregnancy prevented is far safer than any pregnancy outcome. However, rural and disadvantaged populations in Canada are inequitably challenged to prevent unintended pregnancy, as cited in the recent report from the UN High Commission. ${ }^{6}$ Canada needs policies, such as universal free contraception and universal access to medical abortion, ${ }^{11}$ that will ensure that all women are equitably supported in the prevention and management of unintended pregnancy.

\section{References}

1. Liu N, Vigod SN, Farrugia MM, et al. Physician procedure volume and related adverse events after surgical induced abortion: a population-based cohort study. CMAJ 2019;191:E519-28.

2. Raymond EG, Grimes DA. The comparative safety of legal induced abortion and childbirth in the United States. Obstet Gynecol 2012;119:215-9.

3. White K, Carroll E, Grossman D. Complications from first-trimester aspiration abortion: a systematic review of the literature. Contraception 2015;92:422-38.

4. Joseph KS, Liu S, Rouleau J, et al. Severe maternal morbidity in Canada, 2003 to 2007: surveillance using routine hospitalization data and ICD-10CA codes. J Obstet Gynaecol Can 2010;32:837-46.

5. Grimes DA, Creinin MD. Induced abortion: an overview for internists. Ann Intern Med 2004;140:620-6.

6. United Nations Human Rights Office of the High Commissioner. Committee on the Elimination of Discrimination against Women. Concluding observations on the combined eighth and ninth periodic reports of Canada. CEDAW/C/CAN/CO/89. Heidelberg (Germany): ETO Consortium Secretariat; 2016:13. Available: www. westcoastleaf.org/wp-content/uploads/2016/11/2016-Canada-CEDAW-Concluding -Obs.pdf (accessed 2019 Apr. 29).

7. Sethna C, Doull M. Spatial disparities and travel to freestanding abortion clinics in Canada. Womens Stud Int Forum 2013;38:52-62.

8. Taylor D, Upadhyay UD, Fjerstad M, et al. Standardizing the classification of abortion incidents: the Procedural Abortion Incident Reporting and Surveillance (PAIRS) Framework. Contraception 2017;96:1-13.

9. Jatlaoui TC, Boutot ME, Mandel MG, et al. Abortion surveillance - United States, 2015. MMWR Surveill Summ 2018;67:1-45.

10. Dunn S, Brooks M. Mifepristone. CMAJ 2018;190:E688.

11. Jayatunga W. Contraception: economic analysis estimation of the Return on Investment (ROI) for publicly funded contraception in England. Gateway no. 2018172. London (UK): Public Health England; 2018. Available: https://assets. publishing.service.gov.uk/government/uploads/system/uploads/attachment_data/ file/730292/contraception_return_on_investment_report.pdf (accessed 2019 Apr. 24).
Competing interests: Wendy Norman is a member of the Board of Directors of the Society for Family Planning. No other competing interests were declared.

This article was solicited and has not been peer reviewed.

Affiliations: Department of Family Practice (Schummers, Norman), University of British Columbia, Vancouver, BC; Faculty of Public Health and Policy (Norman), London School of Hygiene \& Tropical Medicine, London, UK
Contributors: Wendy Norman conceived the work and Laura Schummers drafted it. Both authors contributed to the design of the manuscript, revised it critically for important intellectual content, gave final approval of the version to be published and agreed to be accountable for all aspects of the work.

Funding: Laura Schummers is supported by a Michael Smith Foundation for Health Research, Research Trainee Award (grant no. 17934) and a Postdoctoral Health System Impact Fellowship co-funded by the BC Ministry of Health (grant no. 18183) and the Canadian Institutes of Health Research (CIHR; grant no. HI7-160383). Wendy Norman is supported as a scholar of the Michael Smith Foundation for Health Research (20125139 HSR) and as an Applied Public Health Research Chair by CIHR and the Public Health Agency of Canada (CPP-329455-107837). Infrastructure support was provided by the Women's Health Research Institute of the Provincial Health Services Authority of British Columbia.

Correspondence to: Wendy Norman, wendy. norman@ubc.ca 